\title{
Development of a
}

Thermodynamic Database for New Fuel Alloy Design

Nuclear Technology

Research and Development

Prepared for U.S. Department of Energy Advanced Fuels Campaign Chao Jiang, Robert Mariani INL National Laboratory September 2017 NTRD-FUEL-2017-000127 



\section{DISCLAIMER}

This information was prepared as an account of work sponsored by an agency of the U.S. Government. Neither the U.S. Government nor any agency thereof, nor any of their employees, makes any warranty, expressed or implied, or assumes any legal liability or responsibility for the accuracy, completeness, or usefulness, of any information, apparatus, product, or process disclosed, or represents that its use would not infringe privately owned rights. References herein to any specific commercial product, process, or service by trade name, trade mark, manufacturer, or otherwise, does not necessarily constitute or imply its endorsement, recommendation, or favoring by the U.S. Government or any agency thereof. The views and opinions of authors expressed herein do not necessarily state or reflect those of the U.S. Government or any agency thereof. 



\section{SUMMARY}

The scope of this FY17 milestone involves the development of a thermodynamic database for the Mo-Ti-Zr ternary system to support the design of new pseudo-binary actinide-M fuel alloy, where $\mathrm{M}$ is a ternary metallic additive composed of Mo, Ti and Zr. Optimization of thermodynamic parameters for the three binary subsystems, Mo-Zr, Mo-Ti and $\mathrm{Zr}-\mathrm{Ti}$, has been performed using the CALPHAD (CALculation of PHAse Diagrams) approach with inputs from both experiments gathered from the literature and density functional theory (DFT) total energy calculations performed in this work. Using the present database, the stability range of the bcc phase in the Mo-Ti-Zr ternary system is predicted and the results are in very good agreement with available experimental data at $600^{\circ} \mathrm{C}$ and $750^{\circ} \mathrm{C}$. The present work can directly contribute to the future development of a multicomponent thermodynamic database for the quaternary U-Mo-Ti-Zr system. 


\section{CONTENTS}

SUMMARY iii

ACRONYMS vii

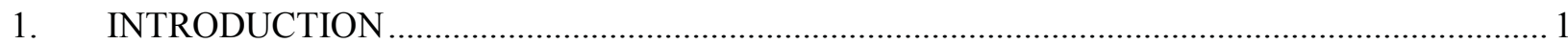

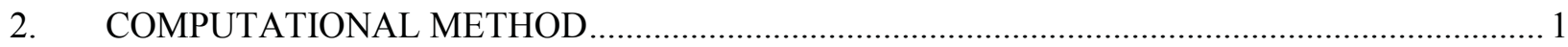

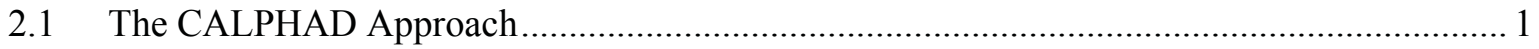

2.2 Density Functional Theory Calculations .................................................................................. 3

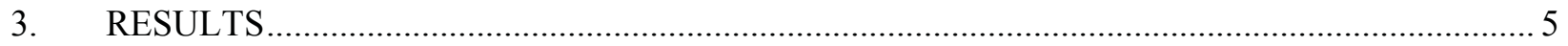

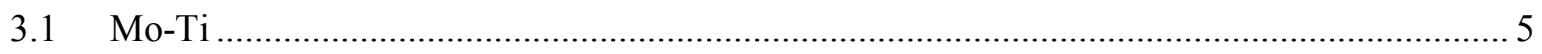

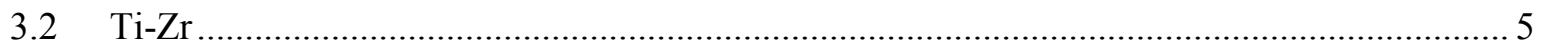

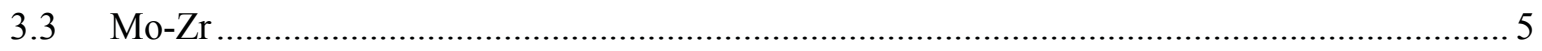

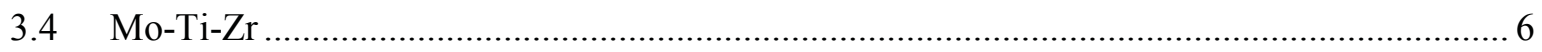

3.5 Phase Stability of Metallic Additives........................................................................... 7

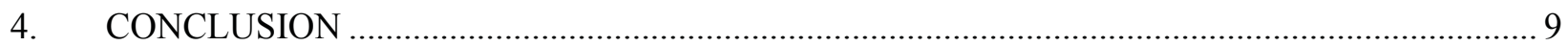

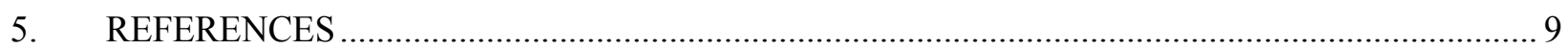

FIGURES

Figure 1. The CALPHAD method for computational thermodynamic modeling of materials....................2

Figure 2. Model predicted liquid mixing energies in comparisons with AIMD results.............................. 3

Figure 3. Model predicted Mo-Ti binary phase diagram in comparison with experiments........................ 4

Figure 4. Model predicted Ti-Zr binary phase diagram in comparison with experiments..........................5

Figure 5. Model predicted Mo-Zr binary phase diagram in comparison with experiments........................ 6

Figure 6. Model predicted Mo-Zr binary phase diagram with the $\mathrm{Mo}_{2} \mathrm{Zr}$ laves phase excluded................. 6

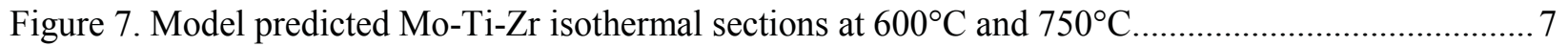

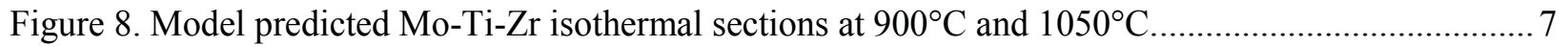

Figure 9. Model predicted equilibrium phase fractions for $\mathrm{Mo}_{35} \mathrm{Ti}_{60} \mathrm{Zr}_{5}$ vs. temperature......................... 8

Figure 10. Model predicted equilibrium phase fractions for $\mathrm{Mo}_{15} \mathrm{Ti}_{70} \mathrm{Zr}_{15}$ vs. temperature....................... 8

\section{TABLES}

Table 1. Thermodynamic parameters for the Mo-Ti-Zr ternary system optimized in this work.

Parameters reported by previous studies in the literature are also shown. 


\section{ACRONYMS}
AIMD Ab Initio Molecular Dynamics
CALPHAD CALculation of PHAse Diagrams
DFT Density Functional Theory
GGA generalized gradient approximation
PBE Perdew-Burke-Ernzerhof
SGTE Scientific Group Thermodata Europe
VASP Vienna ab initio simulation package 


\section{DEVELOPMENT OF A THERMODYNAMIC DATABASE FOR NEW FUEL ALLOY DESIGN}

\section{INTRODUCTION}

Alloying pure actinides such as uranium (U) with metallic additives is a viable way to produce nuclear fission fuels with increased burnup (fuel utilization) and improved chemical, thermal, and mechanical properties. For example, compared with pure $\mathrm{U}$, a pseudo-binary $\mathrm{U}-x \mathrm{M}$ fuel mixture can simultaneously exhibit higher solidus temperature and enhanced phase stability of body-centered cubic (bec) $\gamma-U$ at low temperature against phase transformation to $\alpha-\mathrm{U}$. Here, $\mathrm{M}$ is a metallic additive that can be an elemental metal or an alloy of metals, and $x$ is its relative amount. For candidates of $\mathrm{M}$, it is known from binary phase diagrams that both zirconium ( $\mathrm{Zr}$ ) and titanium (Ti) can increase the melting point of $\gamma-\mathrm{U}$, while Mo is a strong $\gamma$-U stabilizer and can significantly depress the bcc-phase onset temperature. By using a ternary Mo-Ti-Zr alloy as metallic additive, it is possible to combine the beneficial properties of these individual elements. To this end, it is necessary to optimize the composition of the ternary metallic additive and its amount in order to achieve the best fuel performance.

As the first step towards developing a thermodynamic database for U-Mo-Ti-Zr quaternary system that can be directly used to guide the design of advanced metallic fuel alloys, the Mo-Ti-Zr ternary system has been first assessed in FY17 using the CALPHAD approach as implemented in the Thermo-Calc software. The necessary inputs have been obtained from both experimental measurements gathered from a thorough review of the literature and Density Functional Theory (DFT) total energy calculations performed in this work. Remarkably, with the incorporation of highly predictive DFT energetics, a high fidelity thermodynamic description of the Mo-Ti-Zr ternary system can be obtained even with very scarce experimental data. The bcc single-phase region in the Mo-Ti-Zr phase diagram predicted by this model is in very good agreement with experimental measurements at both $600^{\circ} \mathrm{C}$ and $750^{\circ} \mathrm{C}$, although none of these ternary experimental data has been used in the optimization process.

\section{COMPUTATIONAL METHOD}

\subsection{The CALPHAD Approach}

As illustrated in Figure 1, CALPHAD (CALculation of PHAse Diagrams) is a self-consistent approach that links thermodynamic and phase diagram data of multi-component systems using phenomenological models that describe Gibbs free energies of phases as a function of temperature and composition. The unique strength of the CALPHAD method is that it allows a ternary A-B-C phase diagram to be predicted using only the free energies of phases in its binary subsystems A-B, A-C and B-C, assuming that no ternary phases exist. Such predictions are highly valuable when experimental data for a ternary system are scarce, which is the case for Mo-Ti-Zr system.

The Gibbs energies of pure Mo, Ti and $\mathrm{Zr}$ in their stable and metastable states are taken from the Scientific Group Thermodata Europe (SGTE) pure element database, with the reference state being the enthalpies of the pure elements in their stable states at $298.15 \mathrm{~K}$, commonly referred to as Standard Element Reference. The substitutional solution model is used to describe the liquid, bec and hep solution phases. Assuming random mixing of $\mathrm{A}$ and $\mathrm{B}$ atoms on a lattice and thus neglecting the effects of short-range ordering, the free energy of a A-B solution phase can be written using Equation 1, where $\Phi=$ liquid, bcc or hcp. The excess term shown in Equation 2 is used to characterize the deviation of real alloys from the ideal solution behavior, and is expressed as a Redlich-Kister polynomial. ${ }^{k} \mathrm{~L}$ is the kth interaction parameter between $\mathrm{A}$ and $\mathrm{B}$ atoms and can be temperature-dependent in the form ${ }^{\mathrm{k}} \mathrm{L}=\mathrm{a}+\mathrm{bT}$. Finally, intermetallic compounds with negligible homogeneity ranges (such as $\mathrm{Mo}_{2} \mathrm{Zr}$ Laves phase in the Mo-Zr system) are modeled as line compounds, and their free energies are described using Equation 3, where the coefficients $a$ and $b$ are the enthalpy and entropy of formation of the compound, respectively. 
Equation 1. Gibbs free energy of A-B random solution phase

$$
G_{m}^{\Phi}=x_{A}{ }^{\circ} G_{A}^{\Phi}+x_{B}{ }^{\circ} G_{B}^{\Phi}+R T\left(x_{A} \ln x_{A}+x_{B} \ln x_{B}\right)+\Delta G_{\text {excess }}^{\Phi}
$$

Equation 2. Excess Gibbs free energy

$$
\Delta G_{\text {excess }}^{\Phi}=X_{A} X_{B} \sum_{k=0}^{n}{ }^{k} L_{A B}^{\Phi}\left(x_{A}-x_{B}\right)^{k}
$$

Equation 3. Gibbs free energy of a $A_{1-x} B_{x}$ line compound

$$
{ }^{\circ} G_{m}^{A_{1-x} B_{x}}=(1-x)^{\circ} G_{A}^{\Phi_{A}}+X^{\circ} G_{B}^{\Phi_{B}}+a+b T
$$

In this work, the unknown parameters are obtained by fitting to both DFT energies and experimental phase equilibrium data, such as liquidus, solidus, and invariant reaction temperatures. The optimization of model parameters is performed using the Parrot module in Thermo-Calc, which works by minimizing the weighted sum of differences between calculated and experimentally measured values using nonlinear least-square regression. Different types of experimental data, e.g., thermochemical and phase equilibrium ones, are optimized simultaneously. The weight for each piece of experimental data is chosen according to its experimental uncertainty and relative importance. A final global optimization is performed, in which all unknown model parameters are optimized simultaneously, with all experimental data included. This ensures the best possible agreement between model calculations and experimental data. The final optimized model parameters are given in Table 1. Optimized parameters from previous studies in the literature [1-3] are also shown for comparison.

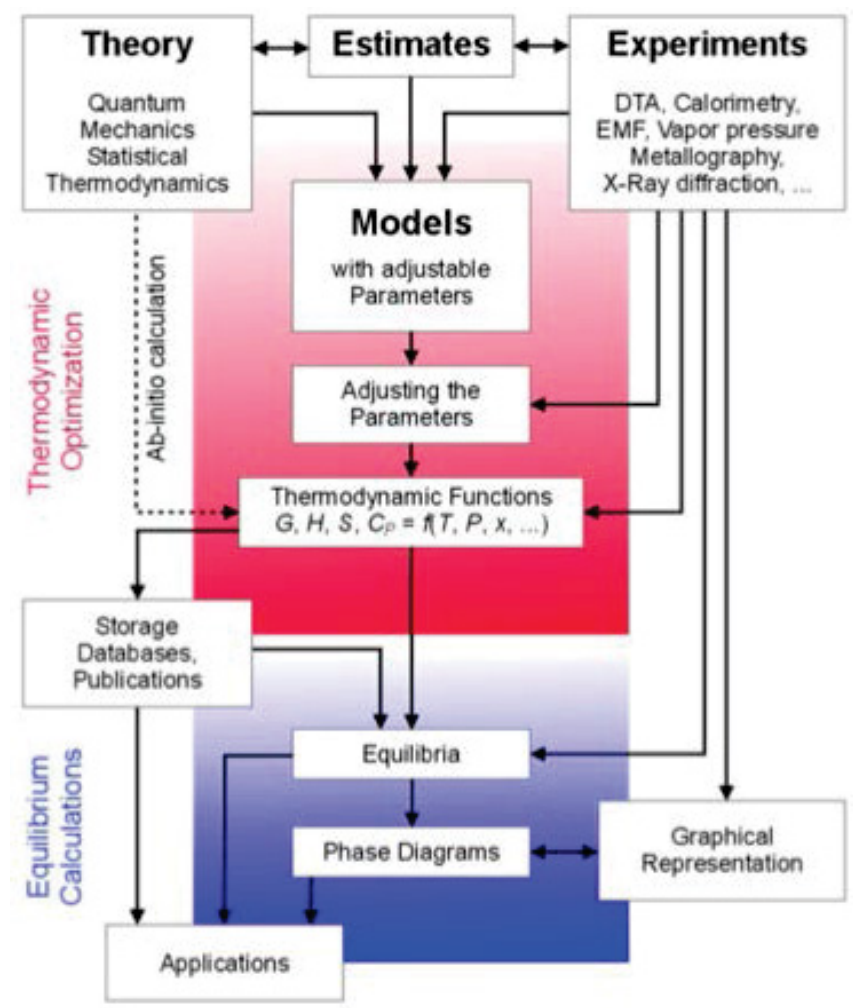

Figure 1. The CALPHAD method for computational thermodynamic modeling of materials. 


\subsection{Density Functional Theory Calculations}

DFT calculations are performed using the projector augmented wave method within the generalized gradient approximation (GGA), as implemented in the Vienna ab initio simulation package (VASP). For the GGA exchange-correlation functional, we employ the Perdew-Burke-Ernzerhof (PBE) parameterization. The semi-core $3 p$ electrons of Ti, the semi-core $4 p$ electrons of Mo, and both the semi-core $4 \mathrm{~s}$ and $4 \mathrm{p}$ electrons of $\mathrm{Zr}$ are explicitly treated as valence electrons. The plane wave cutoff energy is set at $300 \mathrm{eV}$. The k-point meshes for Brillouin zone sampling are constructed using the Monkhorst-Pack scheme, and the total number of k-points times the total number of atoms per unit cell is at least 5000 for all structures. Convergence tests show that the chosen cutoff energy and k-point density are sufficient to guarantee high numerical accuracy. By computing the quantum-mechanical forces and stress tensor, the unit cell volume and shape as well as all internal atomic positions of all structures are fully relaxed using a conjugate-gradient scheme.

$\mathrm{Ab}$ initio molecular dynamics (AIMD) simulations based on density functional theory have been performed to model the liquid state of Mo-Ti, Mo-Zr and Ti-Zr alloys at a constant temperature of $3000 \mathrm{~K}$. Due to constraint of computing resources, a 128-atom cubic supercell is used for all liquids. Simulations are performed in a canonical ensemble with the cell volume adjusted to give zero total pressure. The time step is $2 \mathrm{fs}$. All liquid alloys are first equilibrated at $3000 \mathrm{~K}$ for $20 \mathrm{ps}$. For temperature control during the equilibration stage, velocity rescaling is performed every 50 time steps. Finally, to obtain the time-averaged thermodynamic properties of liquid phases, AIMD run is performed for a total duration of $10 \mathrm{ps}$ using Nose thermostat for temperature control. To ensure high accuracy, a $2 \times 2 \times 2$ k-point mesh is used to sample the Brillouin zone. As shown in Figure 2, the model calculated mixing energies of liquid phases in the Mo-Ti, Mo-Zr and Ti-Zr systems are in good agreement with present AIMD results.
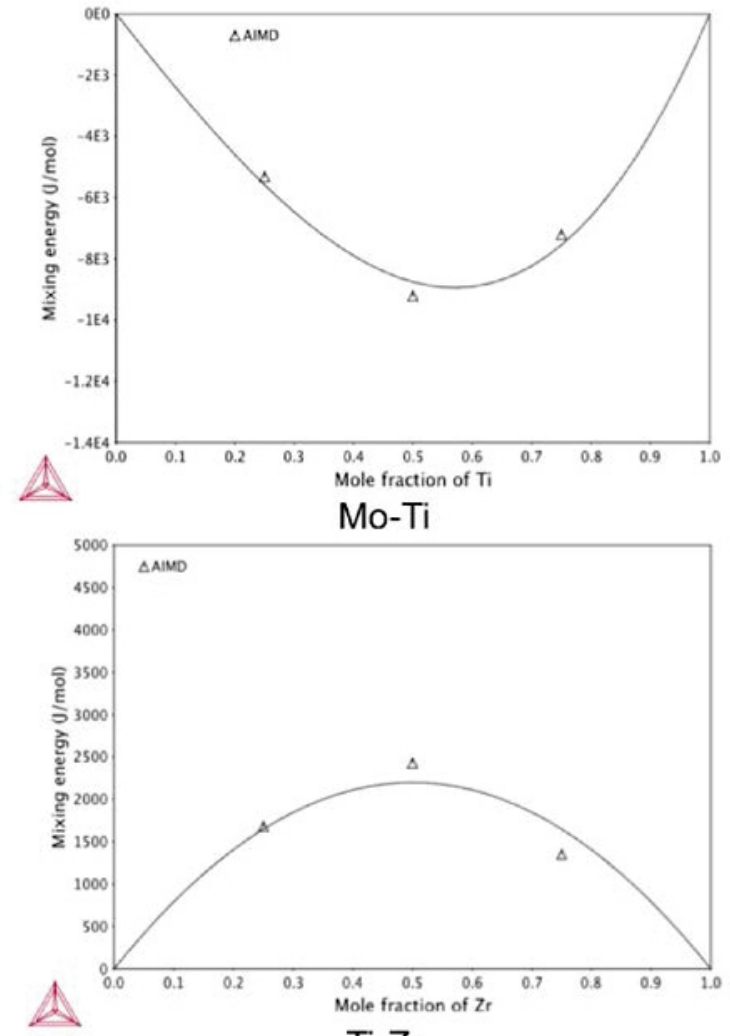

$\mathrm{Ti}-\mathrm{Zr}$

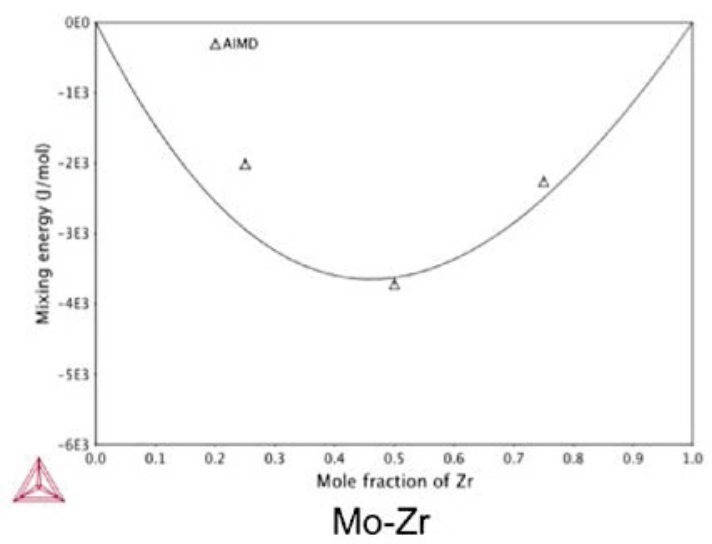

Figure 2. Model predicted liquid mixing energies in comparisons with AIMD results. 
Table 1. Thermodynamic parameters for the Mo-Ti-Zr ternary system optimized in this work. Parameters reported by previous studies in the literature are also shown.

\begin{tabular}{|c|c|c|c|c|}
\hline System & Phase & Parameter & This work & Previous studies \\
\hline \multirow{7}{*}{ Mo-Ti } & \multirow{3}{*}{$\mathrm{Bcc}$} & $\mathrm{L}_{0}$ & -44446 & $+2000 \quad[1]$ \\
\hline & & $\mathrm{L}_{1}$ & -26852 & $-2000 \quad[1]$ \\
\hline & & $\mathrm{L}_{2}$ & -8713 & $0 \quad[1]$ \\
\hline & \multirow{2}{*}{ Liquid } & $\mathrm{L}_{0}$ & $-35014-6.665 * \mathrm{~T}$ & $-9000+2 * \mathrm{~T} \quad[1]$ \\
\hline & & $\mathrm{L}_{1}$ & $+10466-13.575 * \mathrm{~T}$ & $0 \quad[1]$ \\
\hline & \multirow{2}{*}{ Hcp } & $\mathrm{L}_{0}$ & -2139 & $+22760-6 * \mathrm{~T} \quad[1]$ \\
\hline & & $\mathrm{L}_{1}$ & -14869 & $0 \quad[1]$ \\
\hline \multirow{6}{*}{ Mo-Zr } & \multirow{2}{*}{$\mathrm{Bcc}$} & $\mathrm{L}_{0}$ & $+14286+3.337 * \mathrm{~T}$ & $+17936+3.102 * \mathrm{~T} \quad$ [2] \\
\hline & & $\mathrm{L}_{1}$ & +7867 & $-991+4.299 * \mathrm{~T} \quad[2]$ \\
\hline & \multirow{2}{*}{ Liquid } & $\mathrm{L}_{0}$ & $-14507+2.247 * \mathrm{~T}$ & $-24055+8.146 * \mathrm{~T}$ \\
\hline & & $\mathrm{L}_{1}$ & $-2373+4.144 * \mathrm{~T}$ & $-5132+4.804 * \mathrm{~T} \quad[2]$ \\
\hline & Hcp & $\mathrm{L}_{0}$ & +73028 & $26754+4.556 * \mathrm{~T} \quad[2]$ \\
\hline & $\mathrm{Mo}_{2} \mathrm{Zr}$ & $\Delta \mathrm{G}_{\text {for }}$ & $-39080+7.803 * \mathrm{~T}$ & $-21735+0.144 * \mathrm{~T}$ \\
\hline \multirow{3}{*}{$\mathrm{Ti}-\mathrm{Zr}$} & $\mathrm{Bcc}$ & $\mathrm{L}_{0}$ & $+11403-5.408 * \mathrm{~T}$ & $-4346+5.489 * \mathrm{~T}$ \\
\hline & Liquid & $\mathrm{L}_{0}$ & $+8799-7.744 * \mathrm{~T}$ & $-968 \quad[3]$ \\
\hline & Hcp & $\mathrm{L}_{0}$ & $+23529-13.557 * \mathrm{~T}$ & $+5133 \quad[3]$ \\
\hline
\end{tabular}

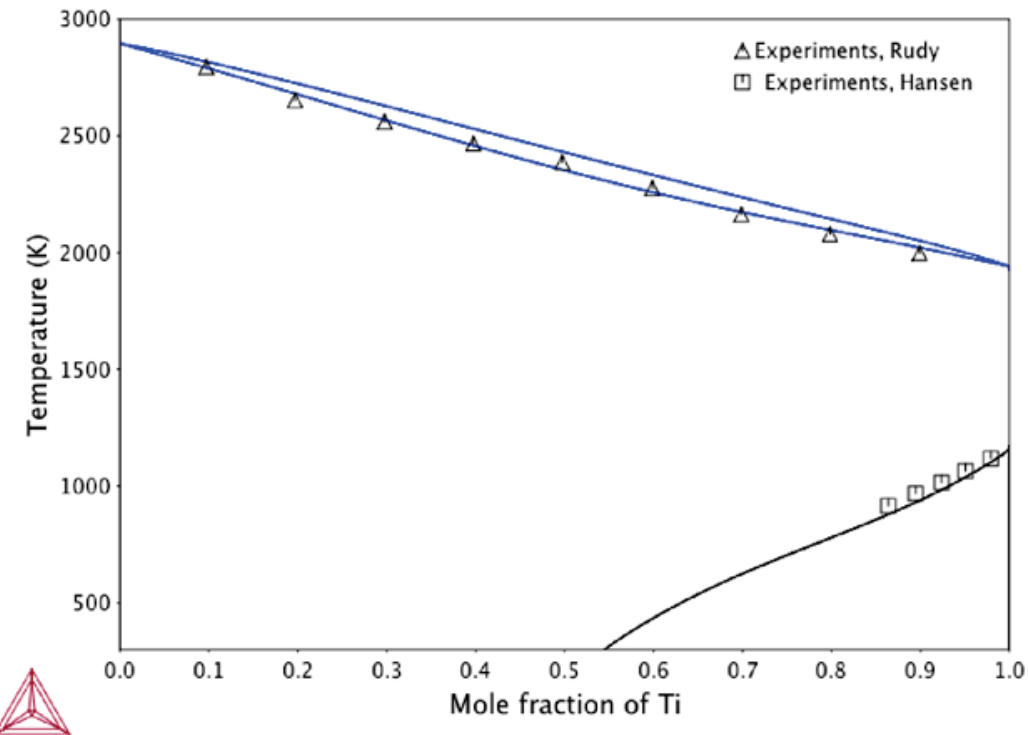

Figure 3. Model predicted Mo-Ti binary phase diagram in comparison with experiments. 


\section{RESULTS}

\subsection{Mo-Ti}

Experimental phase diagram data for Mo-Ti system have been reviewed by Murray [4]. In this system, there exist three equilibrium solution phases: liquid, bcc, and hcp. For pure Ti, an hcp-to-bcc phase transition will occur at around $882^{\circ} \mathrm{C}$. Such a temperature is significantly depressed with the addition of Mo, which is stable in the bcc structure at all temperatures until melting. As shown in Figure 3, the calculated Mo-Ti phase diagram is in good agreement with the experimental solidus data from Rudy [5] and $\mathrm{bcc} / \mathrm{hcp}$ phase boundary data from Hansen et al. [6].

\section{$3.2 \mathrm{Ti}-\mathrm{Zr}$}

Experimental phase diagram data for Ti-Zr system have been reviewed by Murray [7]. Similar to Mo-Ti, liquid, bcc, and hcp are the only equilibrium phases in this system. Since both pure Ti and Zr are stable in the hep structure at low temperatures, a continuous hep solid solution is formed in this system. As shown in Figure 4, the calculated Ti-Zr phase diagram is in excellent agreement with the experimental solidus data from Rudy [5] and bcc/hcp phase boundary data from Hansen and Alder [8].

\subsection{Mo-Zr}

The Mo-Zr phase diagram has been experimentally investigated by Garg and Ackermann [9] and by Domagala et al. [10]. In addition to the liquid, bcc, and hep solution phases, an intermetallic compound $\mathrm{Mo}_{2} \mathrm{Zr}$ with Laves $\mathrm{C} 15$ crystal structure also exists in this system, which is formed from the peritectic reaction "bcc + liquid $=\mathrm{Mo}_{2} \mathrm{Zr}$ " at around $1880^{\circ} \mathrm{C}$. At the $\mathrm{Zr}$-rich side, liquid will eutectically decompose into a mixture of $\mathrm{Mo}_{2} \mathrm{Zr}$ and bcc via the reaction "liquid $=\mathrm{Mo}_{2} \mathrm{Zr}+$ bcc" at around $1520^{\circ} \mathrm{C}$. The third invariant reaction is the eutectoid reaction " $\mathrm{bcc}=\mathrm{Mo}_{2} \mathrm{Zr}+\mathrm{hcp}$ " that occurs at around $780^{\circ} \mathrm{C}$. As shown in Figure 5, overall, the calculated Mo-Zr phase diagram is in good agreement with the experimental data [9, 10]. In this work, the limited homogeneity range of $\mathrm{Mo}_{2} \mathrm{Zr}$ is neglected, and it is treated as a line compound. Due to the formation of $\mathrm{Mo}_{2} \mathrm{Zr}$, the solubility of $\mathrm{Zr}$ in bcc Mo is very small even at $1000 \mathrm{~K}$. Figure 6 further shows the calculated Mo-Zr phase diagram assuming that the $\mathrm{Mo}_{2} \mathrm{Zr}$ compound does not form. In this case, the phase diagram shows a complete solubility in the bcc phase at high temperature, similar to $\mathrm{Mo}-\mathrm{Ti}$, and a bec miscibility gap at low temperature.

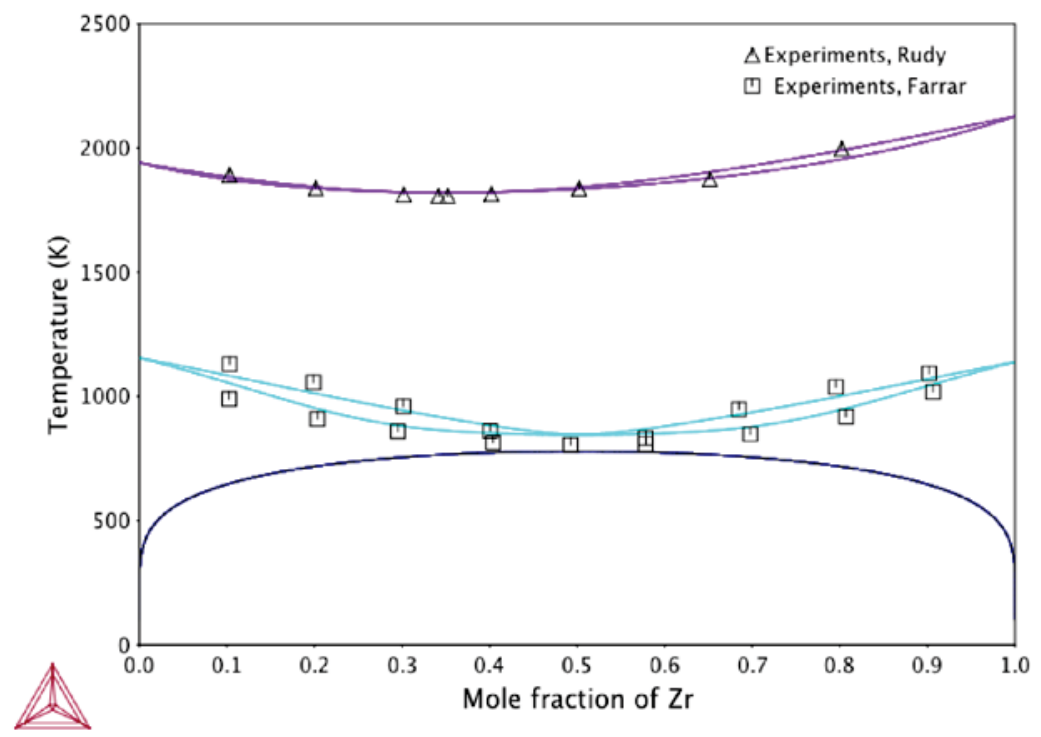

Figure 4. Model predicted Ti-Zr binary phase diagram in comparison with experiments. 


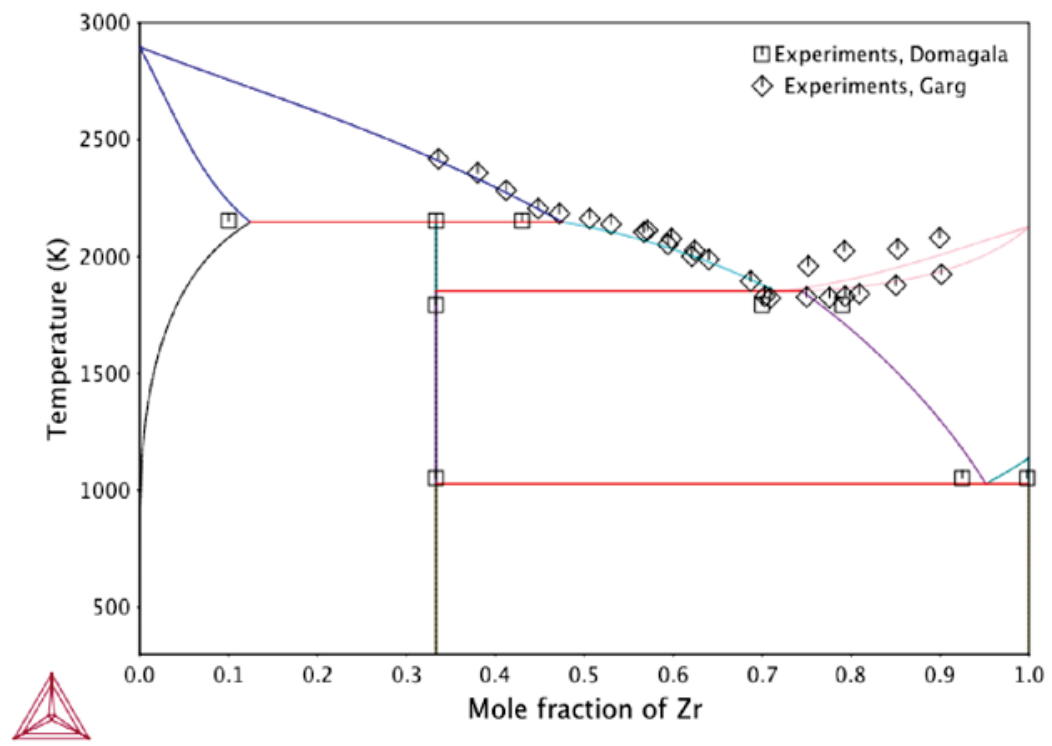

Figure 5. Model predicted Mo-Zr binary phase diagram in comparison with experiments.

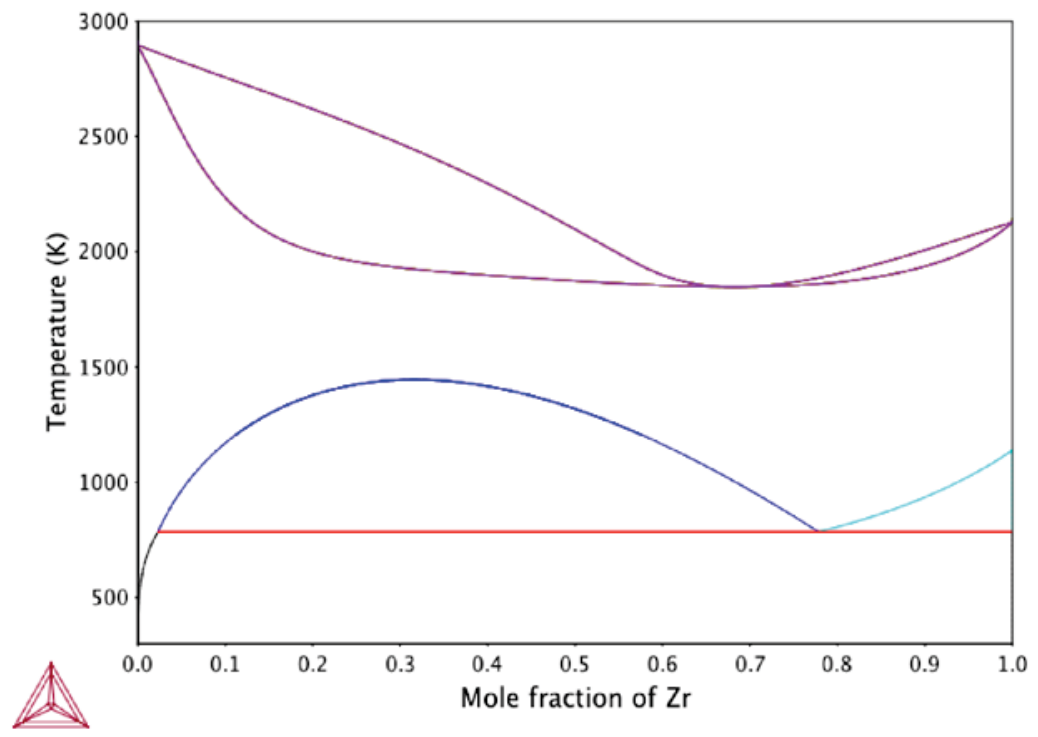

Figure 6. Model predicted Mo-Zr binary phase diagram with the $\mathrm{Mo}_{2} \mathrm{Zr}$ laves phase excluded.

\subsection{Mo-Ti-Zr}

Combining the thermodynamic parameters for Mo-Ti, Mo-Zr and Ti-Zr binary systems optimized in this work (Table 1), the isothermal sections of Mo-Ti-Zr ternary system at $600^{\circ} \mathrm{C}$ and $750^{\circ} \mathrm{C}$ are calculated and compared with the experimental data from Prokoshkin and Zakharova [11]. The results are shown in Figure 7. The green lines are tie-lines and the red triangles indicate three-phase equilibrium. Remarkably, the model predicted bcc single-phase region is in excellent agreement with experimental data (shown by the open symbols), although none of them has been used in the optimization process. This is a direct validation of the predictive power of the present database. Figure 8 further shows the predicted isothermal sections of Mo-Ti-Zr at $900^{\circ} \mathrm{C}$ and $1050^{\circ} \mathrm{C}$. A clear trend can be seen that the single-phase bec region expands with increasing temperature. 

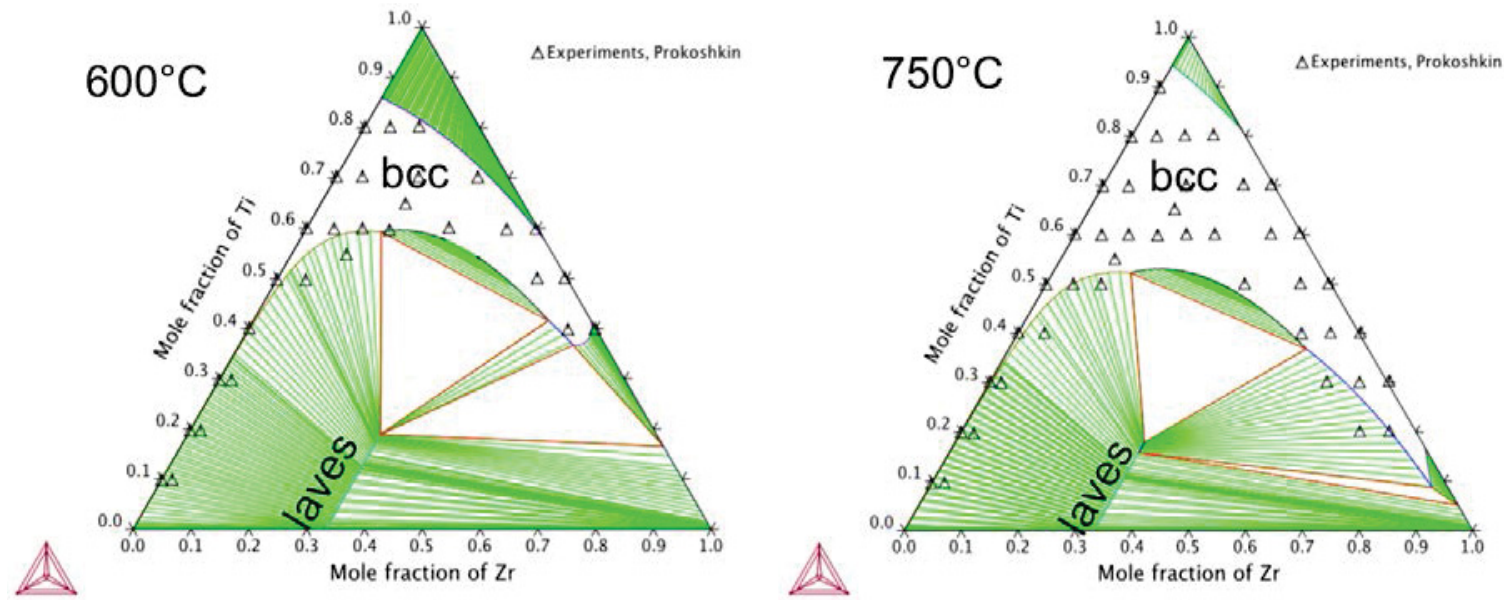

Figure 7. Model predicted Mo-Ti-Zr isothermal sections at $600^{\circ} \mathrm{C}$ and $750^{\circ} \mathrm{C}$.
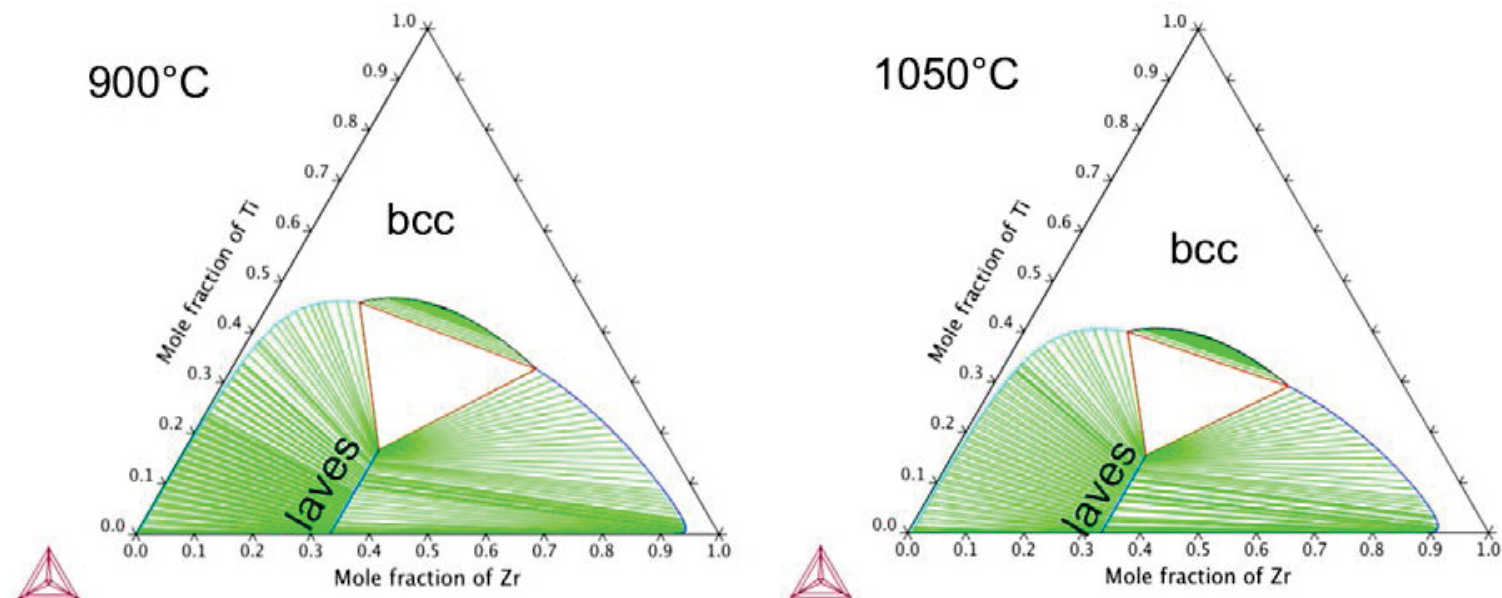

Figure 8. Model predicted Mo-Ti-Zr isothermal sections at $900^{\circ} \mathrm{C}$ and $1050^{\circ} \mathrm{C}$.

\subsection{Phase Stability of Metallic Additives}

Two alloy compositions, $\mathrm{Mo}_{35} \mathrm{Ti}_{60} \mathrm{Zr}_{5}$ (at.\%) and $\mathrm{Mo}_{15} \mathrm{Ti}_{70} \mathrm{Zr}_{15}$ (at.\%), have been chosen as exemplary metallic additives for U. Using the present thermodynamic database, the equilibrium phase fractions of these two alloys are predicted as a function of temperature, and the results are shown in Figure 9 and Figure 10, respectively. It can be seen that the solidus temperature of $\mathrm{Mo}_{35} \mathrm{Ti}_{60} \mathrm{Zr}_{5}(2113 \mathrm{~K})$ is higher than that of $\mathrm{Mo}_{15} \mathrm{Ti}_{70} \mathrm{Zr}_{15}(1915 \mathrm{~K})$, which is presumably due to the higher Mo content in the former. The bcc decomposition temperature, which is defined as the lowest temperature for a single-phase bcc microstructure to be thermodynamically stable, is $833 \mathrm{~K}$ for $\mathrm{Mo}_{35} \mathrm{Ti}_{60} \mathrm{Zr}_{5}$ and $733 \mathrm{~K}$ for $\mathrm{Mo}_{15} \mathrm{Ti}_{70} \mathrm{Zr}_{15}$. At $300 \mathrm{~K}$, about $60 \%$ of the high temperature bcc phase may be retained in $\mathrm{Mo}_{35} \mathrm{Ti}_{60} \mathrm{Zr}_{5}$, while no bcc phase is left in $\mathrm{Mo}_{15} \mathrm{Ti}_{70} \mathrm{Zr}_{15}$. Such a conclusion is consistent with the fact that Mo is a strong bec stabilizer. 


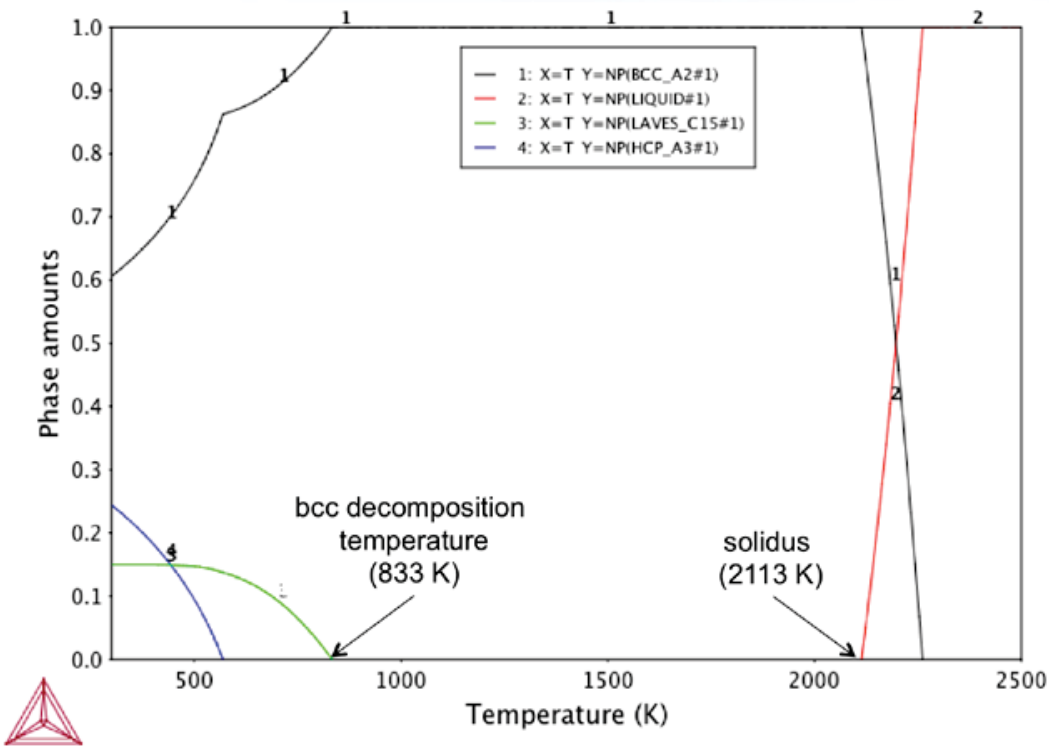

Figure 9. Model predicted equilibrium phase fractions for $\mathrm{Mo}_{35} \mathrm{Ti}_{60} \mathrm{Zr}_{5}$ vs. temperature.

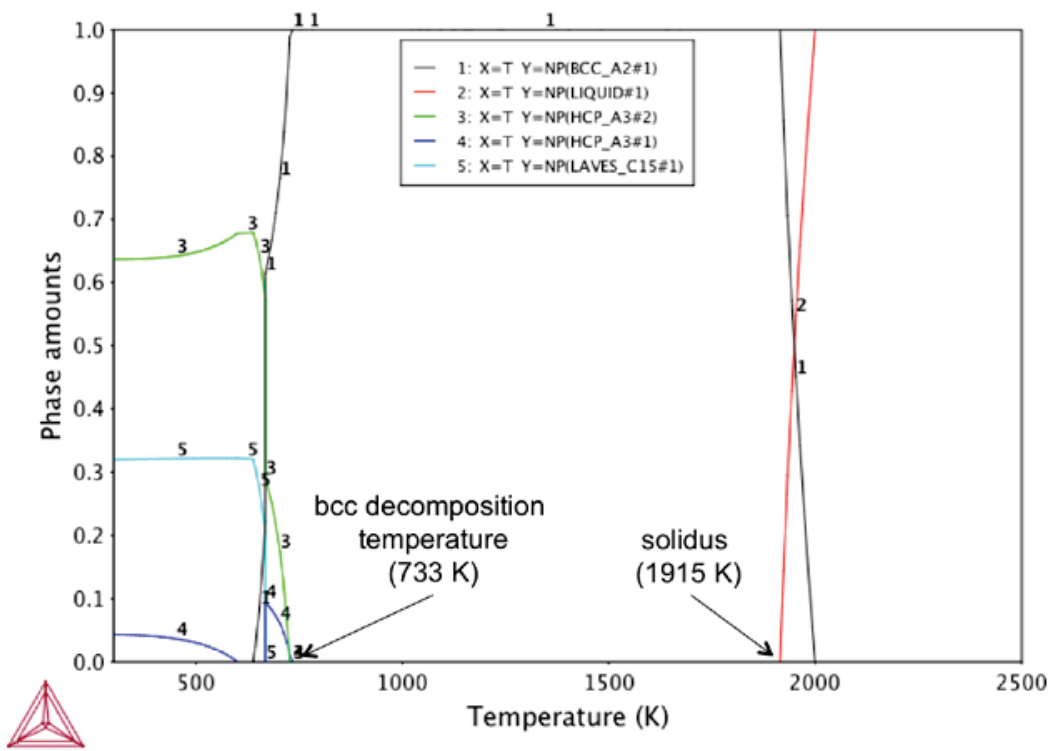

Figure 10. Model predicted equilibrium phase fractions for $\mathrm{Mo}_{15} \mathrm{Ti}_{70} \mathrm{Zr}_{15}$ vs. temperature. 


\section{CONCLUSION}

During FY17, a high fidelity thermodynamic database for the Mo-Ti-Zr ternary system has been developed to assist the design of new pseudo-binary U-M fuel alloy, where M is a bcc Mo-Ti-Zr alloy. The three binary subsystems, Mo-Zr, Mo-Ti and Zr-Ti, have been remodeled using the CALPHAD technique with inputs from both experiments and DFT calculations performed in this work. DFT results are used here to overcome the scarcity of thermodynamic data for these alloys, which is presumably due to the high melting point of Mo and the high reactivity of $\mathrm{Zr}$ with oxygen at high temperatures. The calculated phase diagrams for Mo-Ti, Mo-Zr and Ti-Zr are in good agreement with existing experimental data. Combining thermodynamic parameters for the binary sub-systems, the Mo-Ti-Zr ternary phase diagrams are predicted, and the results show excellent agreement with experiments. Using the present database, the melting temperatures and bcc decomposition temperatures of two exemplary metallic additives, $\mathrm{Mo}_{35} \mathrm{Ti}_{60} \mathrm{Zr}_{5}$ and $\mathrm{Mo}_{15} \mathrm{Ti}_{70} \mathrm{Zr}_{15}$, have been predicted. The present work will contribute to the future development of thermodynamic database for U-Mo-Ti-Zr system.

\section{REFERENCES}

[1] K. Santhy and K.C. Hari Kumar. Thermodynamic assessment of Mo-Ni-Ti ternary system by coupling first-principle calculations with CALPHAD approach. Intermetallics, 18:1713-1721, 2010.

[2] R.J. Perez and B. Sundman. Thermodynamic assessment of the Mo-Zr binary phase diagram. CALPHAD, 27:253-262, 2003.

[3] K.C. Hari Kumar, P. Wollants and L. Delaey. Thermodynamic assessment of the Ti-Zr system and calculation of the Nb-Ti-Zr phase diagram. Journal of Alloys and Compounds, 206:121-127, 1994.

[4] J.L. Murray. The Mo-Ti (molybdenum-titanium) system. Bulletin of Alloy Phase Diagrams, 2:185-192, 1981.

[5] E. Rudy. Compilation of Phase Diagram Data, Technical Report AFML-TR-62-2, Wright Patterson Air Force Base, 1969.

[6] M. Hansen, E.L. Kamen and H.D. Kessler. Systems titanium-molybdenum and titaniumcolumbium. Trans. AIME, 191:881-888, 1951.

[7] J.L. Murray. The Ti-Zr (titanium-zirconium) system. Bulletin of Alloy Phase Diagrams, 2:197-201, 1981.

[8] P.A. Farrar and S. Adler. On the system titanium-zirconium. Trans. AIME, 236:1061-1064, 1966.

[9] S.P. Garg and R.J. Ackermann. The high temperature phase diagrams for zirconium-molybdenum and hafnium-molybdenum. Metallurgical Transactions A, 8:239-244, 1977.

[10] R.F. Domagala, D.J. McPherson and M. Hansen. Systems zirconium-molybdenum and zirconiumwolfram. Trans. AIME, 197:73-79, 1953.

[11] D.A. Prokoshkin and M.I. Zakharova. Isothermal cross sections at 600 and 750C of the phase diagram of the system molybdenum-titanium-zirconium. Inorg. Mat., 3:70-75, 1967. 